\title{
New Sodium Intercalation Cathode Prepared by Sodiation of Delithiated Host $\mathrm{LiNi}_{1 / 3} \mathrm{Mn}_{1 / 3} \mathrm{Co}_{1 / 3} \mathrm{O}_{2}$
}

\author{
Van Hoang Nguyen, ${ }^{1,2,3}$ Le Minh Nguyen, ${ }^{1,3}$ Tuyen Thi Kim Huynh,,3 \\ Van Man Tran, ${ }^{1,2,3}$ and My Loan Phung Le $\mathbb{C}^{1,2,3}$ \\ ${ }^{1}$ Department of Physical Chemistry, Faculty of Chemistry, University of Science, Ho Chi Minh City, Vietnam \\ ${ }^{2}$ Applied Physical Chemistry Laboratory (APCLAB), Faculty of Chemistry, University of Science, Ho Chi Minh City, Vietnam \\ ${ }^{3}$ Vietnam National University, Ho Chi Minh City, Vietnam \\ Correspondence should be addressed to My Loan Phung Le; lmlphung@hcmus.edu.vn
}

Received 16 July 2020; Revised 6 December 2020; Accepted 28 December 2020; Published 27 January 2021

Academic Editor: María Criado

Copyright (c) 2021 Van Hoang Nguyen et al. This is an open access article distributed under the Creative Commons Attribution License, which permits unrestricted use, distribution, and reproduction in any medium, provided the original work is properly cited.

\begin{abstract}
In this work, the layered structure $\mathrm{LiNi}_{1 / 3} \mathrm{Mn}_{1 / 3} \mathrm{Co}_{1 / 3} \mathrm{O}_{2}$ (LiNMC) served as a host to enable sodium-ion intercalation. LiNMC was initially charged in Li-half-cell at $\mathrm{C} / 25$ rate up to $4.5 \mathrm{~V}$ to extract maximum of $\mathrm{Li}^{+}$ions and then discharged at the same rate in $\mathrm{Na}$ half-cell down to $2 \mathrm{~V}$ for full sodiation to form $\mathrm{Na}_{\mathrm{y}} \mathrm{NMC}$ phase. The electrochemical characteristics of the new sodium phase $\mathrm{Na}_{\mathrm{y}} \mathrm{NMC}$ were evaluated by cyclic voltammetry (CV), galvanostatic cycling, and electrochemical impedance spectroscopy (EIS). On the $\mathrm{CV}$ curve, the featured peaks of phase transition induced by $\mathrm{Na}^{+}$intercalation into $\mathrm{Na}_{\mathrm{y}} \mathrm{NMC}$ host could be distinguished from the couple peak located at $3.8 \mathrm{~V}$ upon the $\mathrm{Li}^{+}$intercalation into $\mathrm{Li}_{\mathrm{x}} \mathrm{NMC}$. The high uniformity and crystallinity of the $\mathrm{Na}_{\mathrm{y}} \mathrm{NMC}$ phase enable delivering a good initial capacity of about $120 \mathrm{mAh} \mathrm{g}^{-1}$ with high rate capability up to $5 \mathrm{C}$ rate. Energydispersive X-ray spectroscopy (EDS) confirms the presence of sodium element in the sodiated $\mathrm{Na}_{\mathrm{y}} \mathrm{NMC}$. It was also noticed that the pristine $\mathrm{O}_{3}$-type layered structure remained unchanged after ion exchanging but the lattice parameters increased due to the large size of sodium-ions inserted into the structure.
\end{abstract}

\section{Introduction}

Switching from fossil fuel to green renewable energy has been forcing the significant development of electrical power sources technology due to its versatility and mobility usage. Among them, Li-ion batteries are the best choice for its powerful storage capability and lightweight. However, commercial Li-ion batteries are facing the challenge of lithium depletion for the next few decades as forecasted elsewhere [1-3]. In this context, the emerging of alternative candidates such as $\mathrm{Na}$-ion batteries is unavoidable because of the predictable low fabrication cost of the batteries and the abundance of raw materials used to prepared electrodes $[1,4-6]$.

$\mathrm{NaNi}_{1 / 3} \mathrm{Mn}_{1 / 3} \mathrm{Co}_{1 / 3} \mathrm{O}_{2}$ (NaNMC) with a layered structure and chemical composition inspired by the commercial analog LiNMC has been considered as the promising cathode for Na-ion batteries [7]. Indeed, its high capacity and high operation voltage are beneficial from the robust transition elements $\mathrm{Ni}, \mathrm{Mn}$, and $\mathrm{Co}$ in equal ratio. This cathode material could be prepared by several reaction ways including the sol-gel process, solid-state reaction, or coprecipitation. Hwang et al. synthesized NaNMC material via coprecipitation of metal salts and calcinated at a low temperature of about $750^{\circ} \mathrm{C}$ in 24 hours. The material exhibited a high capacity of $140 \mathrm{mAh} \mathrm{g}^{-1}$ and relatively superior performance in half-cell compared to different ratio of $\mathrm{Ni} / \mathrm{Mn} / \mathrm{Co}$ in the synergistic research [8]. Sathiya and colleagues are pioneers in synthesizing the material NaNMC via a sol-gel process following a calcination step at $900^{\circ} \mathrm{C}$ in 12 hours [9]. The material showed a discharge capacity of $120 \mathrm{mAh} \mathrm{g}^{-1}$ and very stable cycling. Unfortunately, moisture-sensitive hindered the application ability of NaNMC in practical batteries. Besides, it might be quite 
difficult to obtain single-phase NaNMC by sintering in the air due to the complexity of composition [10]. On the contrary, the moisture issue is tolerant in the synthesis of LiNMC, whereas an $\mathrm{O}_{3}$ structure with a low percentage of cation disordering could be obtained by simple calcination $[11,12]$.

The isotropic structure and high crystallization degree of lithium layered compounds are promising to provide a uniform diffusion pathway for sodium-ions [13]. It has been proved that $\mathrm{Li}$-doped sodium layered structures enhance the structural stability and the capacity of the electrode materials $[14,15]$. Reversely, due to the large spacing slab of sodium layered compounds, the sodium compounds demonstrated their potential to intercalate lithium-ions at higher capacity and rate capability $[7,16]$. Therefore, sodiation in delithiated host with the lowest remained lithium-ions is another way to enhance the electrochemical properties of the sodium cathode. Recent studies have reported the use of a delithiated cathode phase as a sodium intercalation host for $\mathrm{Na}$-ion batteries, including layered oxide, phosphates, and Li-rich cathodes [13, 17-20]. Previously, we studied the full sodiation into LiNMC synthesized via sol-gel reaction [13]. The number of $\mathrm{Na}^{+}$ion inserted into the delithiated host is comparable to the number of lithium extracted at $\mathrm{C} / 10$ rate in the voltage range $2-4 \mathrm{~V}$. The diffusion coefficient of $\mathrm{Na}^{+}$ ion into the solid structure calculated from Galvanostatic Intermittence Titration Technique (GITT) is relatively stable with the value range of $1 \times 10^{-9}-7 \times 10^{-10} \mathrm{~cm}^{2} \mathrm{~s}^{-1}$. However, the structure of the sodiated cathode was incompletely investigated. Hence, in this work, the high crystallinity $\mathrm{LiNi}_{1 / 3} \mathrm{Mn}_{1 / 3} \mathrm{Co}_{1 / 3} \mathrm{O}_{2}$ layered cathode (LiNMC) was subjected to sodium-ion-exchange and evaluated the performance in sodium half-cell. The lithium extraction was limited by a cutoff voltage of $4.5 \mathrm{~V}$ to evaluate whether there is more vacancy to uptake sodium-ion. In addition, the structure evolution was further explored after the initial sodiation and consecutive cycling.

\section{Experiment}

2.1. Electrode Preparation. Commercially, $\mathrm{LiNi}_{1 / 3} \mathrm{Mn}_{1 / 3} \mathrm{Co}_{1 / 3} \mathrm{O}_{2}$ (LiNMC) powder was supplied by MTI Corp. Electrode slurry was made from a mixture of LiNMC, carbon C65, and polyvinylidene fluoride-co-hexafluoropropylene (PVdF-HFP) in the weight ratio of 94:3:3 in N-methyl pyrrolidone (NMP) solvent and then ball-milled for thoroughly mixing before coating on $\mathrm{Al}$ foil. The coated $\mathrm{Al}$ foil was dried at $110^{\circ} \mathrm{C}$ in a vacuum for 12 hours and punched into $12 \mathrm{~mm}$ round shapes with mass loading about $3-4 \mathrm{mg} \mathrm{cm}^{-2}$.

\subsection{Electrochemical Ion Exchange to Synthesize NazNMC and} Electrochemical Characterization. The scheme in Figure 1 demonstrates the experimental procedure of ion-exchange. Lithium half-cell, consisting of the LiNMC as a cathode, lithium metal as an anode, and Whatman microfiber GF/C separator wetted by $\mathrm{LiPF}_{6} 1 \mathrm{M} / \mathrm{EC}-\mathrm{DMC}(1: 1)$ electrolyte, was assembled in the glovebox. The cell was charged by the rate of $\mathrm{C} / 25$ ( $1 \mathrm{C}$ corresponding to the extraction of 1 ion per molecular in 1 hour) from the open circuit potential (OCP) to $4.5 \mathrm{~V}$ versus $\mathrm{Li}^{+} / \mathrm{Li}$ then and kept for at least 12 hours to fully extract lithium-ions. Next, the delithiated cathode was taken out in glovebox and soaked many times with dimethyl carbonate (DMC) solvent and finally dried at $100^{\circ} \mathrm{C}$ on the hot plate.

The delithiated cathode was placed again in sodium halfcell using sodium metal as anode and Whatman microfiber $\mathrm{GF} / \mathrm{C}$ wetted by $\mathrm{NaClO}_{4} 1 \mathrm{M} / \mathrm{PC}-\mathrm{FEC}(98: 2)$ electrolyte. The charge-discharge rate of the cell was controlled in galvanostatic mode. The cells were firstly discharged by the rate of $\mathrm{C} / 25$ from OCP to $2.0 \mathrm{~V}$ versus $\mathrm{Na}^{+} / \mathrm{Na}$ to insert $\mathrm{Na}^{+}$ion into the delithiated cathode. Cyclic voltammetry $(\mathrm{CV})$ measurement was performed in the voltage range of 2.0-4.0 V versus $\mathrm{Na}^{+} / \mathrm{Na}$. EIS was conducted before and after cycling by applying the alternative voltage with $10 \mathrm{mV}$ amplitude and the frequency in a range from $1 \mathrm{MHz}$ to $10 \mathrm{mHz}$. All the electrochemical characterization was conducted on MPG-2 and/or VSP high accuracy apparatus (Biologic-France). The Swagelok-type cell was used for ex situ structural characterization to prevent short circuits while coin-cell type CR2032 was used for cycling tests.

$\mathrm{X}$-ray diffraction analysis of the cathode after casting on $\mathrm{Al}$ foil and the cycled cathode on lithium/sodium cells was performed using $\mathrm{CuK} \alpha(\lambda=1.508 \AA)$ with the scan rate of $0.02^{\circ} /$ step/0.25s on D8 Advance Diffractometer (Bruker). Scanning Electron Microscopy (SEM) coupled with energydispersive X-ray spectroscopy (EDS) (S4800 FESEM, Hitachi) was used to evaluate the morphology and element composition of the cathode.

\section{Results and Discussion}

O3 represents the layered structure where the alkaline ions and transition ions occupy sequentially the octahedral sites between the adjacent arrays of hexagonal closed packed oxygens, as seen inside Figure 1. Additionally, there are three repeated layers built of the octahedral of transition metal connected through edges and corners in the unit cell that classified it into $\mathrm{O}_{3}$-type [21]. The $\mathrm{O}_{3}$-type structure could accept almost one alkaline ion per molecular formula.

In this work, the commercial power LiNMC with a high crystallinity degree and uniform grain size distribution was used so that the results are not affected by structure default or particle size distribution. The first charge-discharge of LiNMC in Li-half-cell given in Figure 2(a) exhibits the $S$ shape sloping feature of LiNMC with plateaus at about $3.8 \mathrm{~V}$ due to lithium extraction in solid solution [11, 22]. The number of lithium extracted from the process was calculated from the number of charge input divided by the theoretical maximum charge that gives a value of about 0.69 lithium-ion at a high cutoff voltage of $4.5 \mathrm{~V}$ at $\mathrm{C} / 25$ rate, corresponding to a specific capacity of $190 \mathrm{mAh}^{-1}$. The high specific charge capacity obtained at rate $\mathrm{C} / 25$ was comparable to our synthesized LiNMC [13] but it exceeded the expected value of LiNMC which is about $160-180 \mathrm{~mA} \mathrm{~g}^{-1}$ because of the small charging current. The side reactions such as phase transition of $\mathrm{O}_{3}$-phase due to excessive release of $\mathrm{Li}^{+}$ion and 


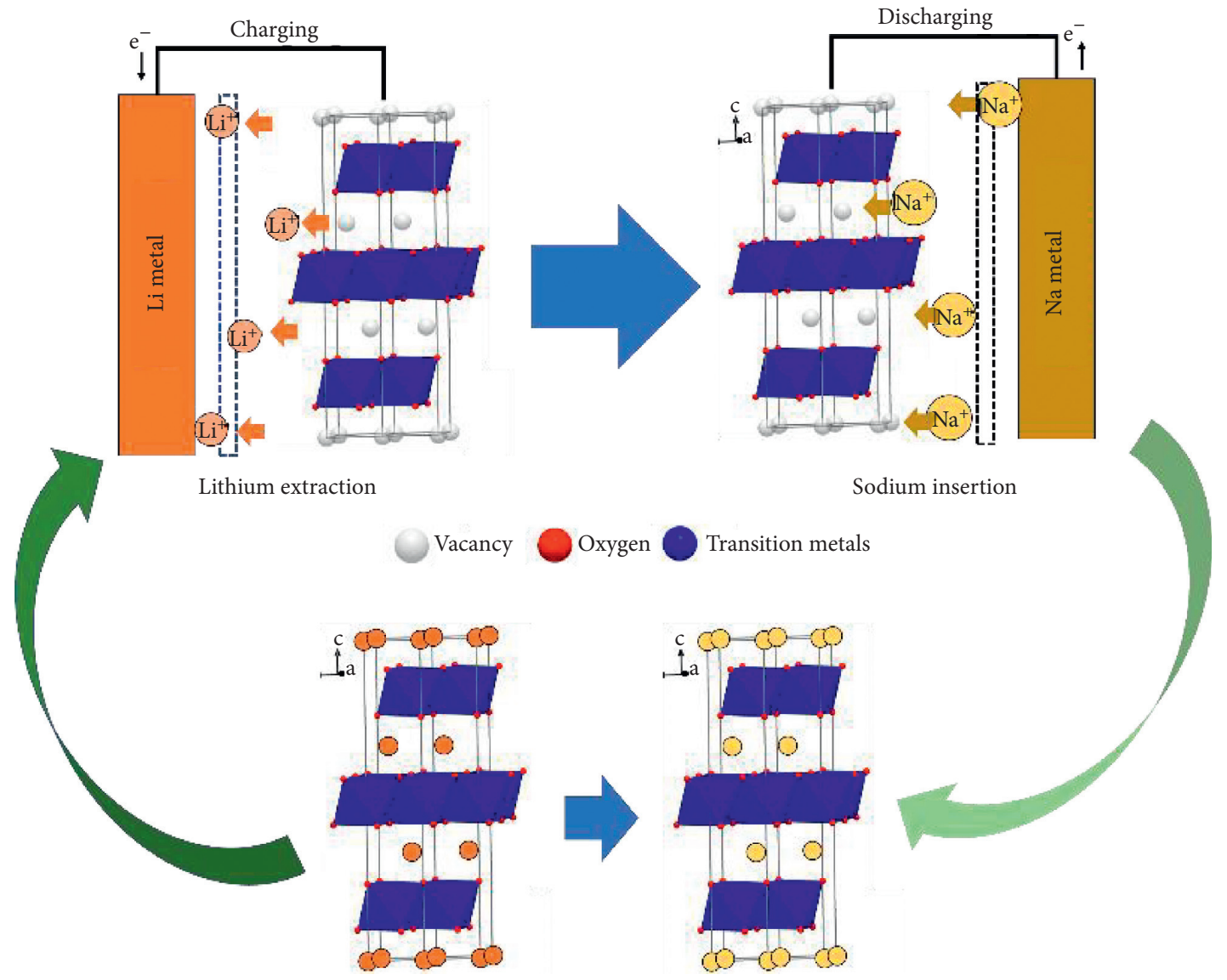

FIGURE 1: Scheme of the electrochemical ion-exchange process to prepare a new sodium insertion compound from a lithium insertion compound. Lithium-ions extracted from LiNMC crystal structure during charging in Li-half-cell then sodium-ions intercalated to the structure during discharging in Na-half-cell.
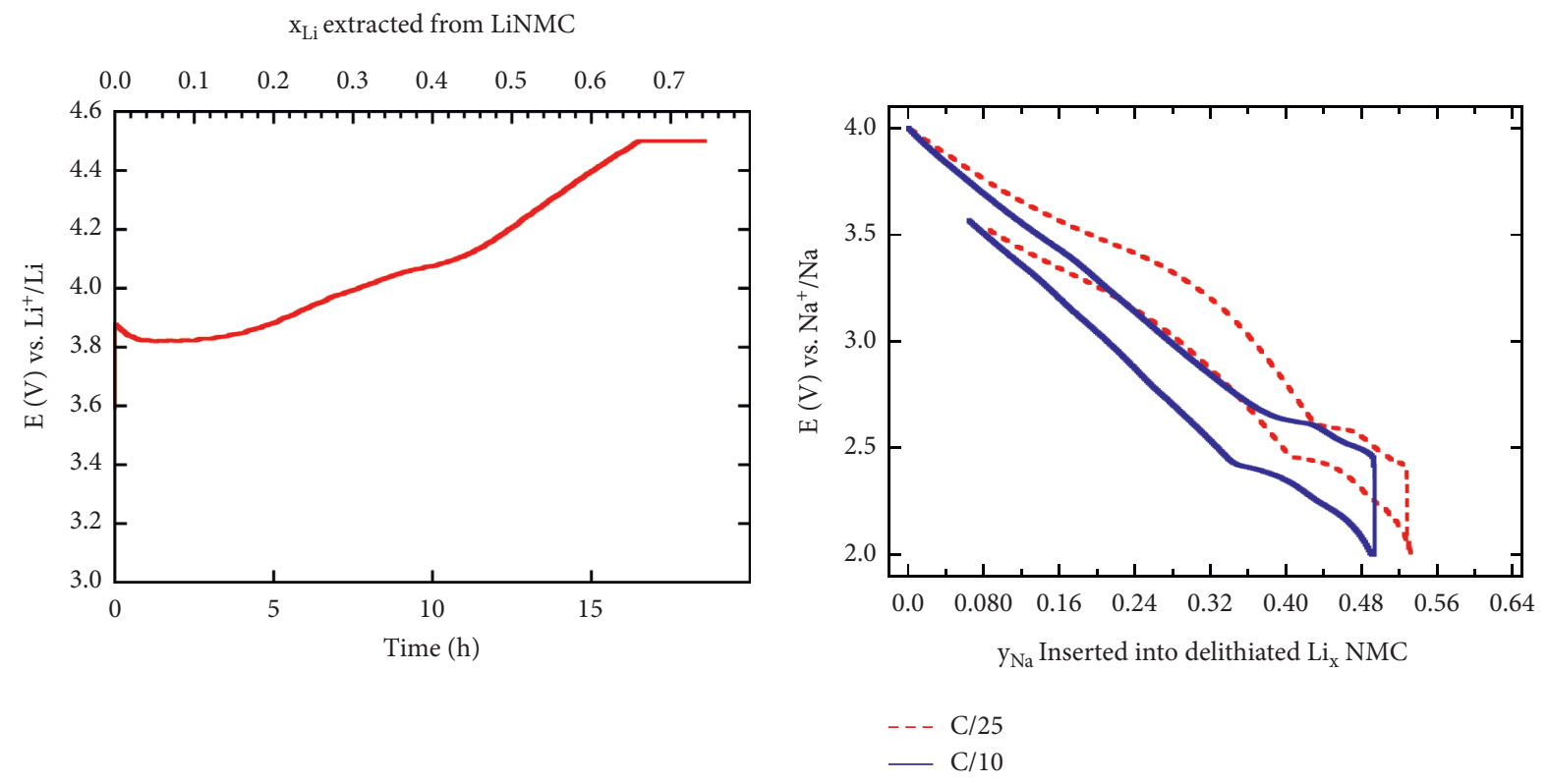

(a)

(b)

Figure 2: (a) Initial charge curve (oxidation state) of LiNMC in half-cell Li $\mid$ LiPF $_{6}$ 1M/EC-DMC (1:1) | LiNMC at C/25 rate. (b) First charge-discharge curve of $\mathrm{Na}_{\mathrm{z}} \mathrm{NMC}$ in half-cell $\mathrm{Na} \mid \mathrm{NaClO}_{4} / \mathrm{PC}$-FEC $(98: 2) \mid \mathrm{Na}_{\mathrm{z}} \mathrm{NMC}$. 
releasing of lattice oxygen $[13,23,24]$ that contributed to structuring destruction and electrolyte composition are probably small contributions to the faradic reaction since the current decreases quickly to the minimum after holding at $4.5 \mathrm{~V}$.

Later, delithiated LiNMC was subjected to be discharged in sodium half-cell and the first voltage profile was given in Figure 2(b). Interestingly, at a low rate of $\mathrm{C} / 25$, an $S$-shape discharge curve appears with an average voltage of about $300 \mathrm{mV}$ lower than that of LiNMC in lithium half-cell followed by flat plateaus in the lower voltage region. The $S$-shape curve is due to the insertion/extraction of the remained lithium in the delithiated host phase. Additionally, a few lithium-ions must be retained to prevent the $\mathrm{O}_{3}$-type layered structure from collapsing. Comparing to the first discharge, in the next charge step, more additional ions including sodium and the remaining lithium-ions could be extracted from the sodiated cathode because of higher cutoff charge voltage than initial OCV. Once the steady charge-discharge state is reached, the maximum ion reversibly exchanged into delithiated LiNMC is about 0.53 ion at a rate of $\mathrm{C} / 25$ which is closed to the maximum value reported for NaNMC in previous studies $[8,9]$. Therefore, the highest value was obtained in the initial intercalation step due to the main contribution of sodium-ion. The amount of sodium-ion intercalated, however, is not equal to the lithium-ion extracted during the oxidation process of LiNMC. In fact, the sodium-ion is bigger than lithium-ion and the electrostatic repulsion between them and the host phase obstructed its replacement for all Li-vacancies. Regarding the first discharge at $\mathrm{C} / 10$, the $S$-shape feature is replaced by discharge curves with a sloping region at high voltage while two short plateaus at $2.6 \mathrm{~V}$ and $2.4 \mathrm{~V}$ due to structural rearrangement during sodium intercalation [9] have remained. The staircase-like voltage profile with voltage jump at a high voltage of NaNMC was replaced by a smooth curve revealing the role of $\mathrm{Li}^{+}$ion as pillar ion to prevent the slab gliding $[14,15,25,26]$. The local structure of $\mathrm{Li}^{+}$ion studied by ${ }^{7} \mathrm{NMR}$ [14] revealed that $\mathrm{Li}^{+}$migration between the sodium-ion slab and the transition metal slab is relatively reversible and is because $\mathrm{Li}^{+}$incapability stabilizes in the prismatic sites instead of the octahedral sites when slabbing gliding during sodium extraction. So, the remaining $\mathrm{Li}^{+}$ion was strapped in the structure to enhance the stability of the sodiated phase.

The electrochemical properties were evaluated after three charges/discharge cycles in the sodium half-cell. In Figure 3(a), CV curves of new cathode exhibited the features differing from LiNMC in lithium half-cell [27] and the highest intensity peak shifted below $2.5 \mathrm{~V}$. According to the voltage profile, this redox couple represents doubling plateaus that could be observed on the curve and its position coincides with the highest potential of couple peak previously reported for the single-phase NaNMC [9]. In addition, several peaks appeared on the oxidation and reduction curves due to sodium intercalation into the host structure. After the first cycle, the consecutive CV curves were almost superposition indicating the steady-state was gained.

The voltage profile along with sodium intercalation is given in Figure 3(b) and the discharge capacity obtained at each cycle is shown in Figure 3(c). It could be seen that the shape of the curve did not completely change but the capacity gradually decreased during cycling. The stable capacity was obtained of about $117 \mathrm{mAh} \mathrm{g}^{-1}(\mathrm{C} / 10)$ at the $50^{\text {th }}$ cycle, corresponding to roughly $85 \%$ capacity retention calculated from the highest capacity of $137 \mathrm{mAh} \mathrm{g}^{-1}(\mathrm{C} / 25)$. At the same time, high Coulombic efficiency of almost 100\% remains during cycling.

The sodiated electrode displayed an excellent rate capability (Figure 3(d)). The capacity slightly decreased when the rate changes from $\mathrm{C} / 10$ to $2 \mathrm{C}$ were applied. At the rate of $2 \mathrm{C}$, the capability remained $105 \mathrm{mAh} \mathrm{g}^{-1}$ corresponding to $74.0 \%$ of its initial capacity at the rate of $\mathrm{C} / 10$. At a rate of $5 \mathrm{C}$, the capacity starts to drop faster but remains at a value of $90 \mathrm{mAh} \mathrm{g}^{-1}$. When it turned back to the original rate $\mathrm{C} / 10$, the capacity delivered is about $96.5 \%$ of its initial capacity.

The sodiated electrode showed a capacity decrease with the cycle at a normal rate of $\mathrm{C} / 10$, as could be seen in Figures 3(c) and 3(d). The structure of the new sodiated cathode was investigated to correlate with its electrochemical performance. As seen in Figure 4(a), XRD patterns of the pristine electrode LiNMC exhibited the peaks of the $\mathrm{O}_{3}$-layered structure $\left(\mathrm{LiCo}_{0.3} \mathrm{Ni}_{0.7} \mathrm{O}_{2}\right.$ as a reference, $\mathrm{PDF} \# 01$ 087-1563). After the first discharge at $2 \mathrm{~V}$, XRD patterns revealed that peaks belonging to the $\mathrm{O}_{3}$-type layered structure of the $\mathrm{O}_{3}-\mathrm{Na}_{\mathrm{y}} \mathrm{NMC}$ phase [9] $\left(\mathrm{NaNi}_{0.5} \mathrm{Mn}_{0.5} \mathrm{O}_{2}\right.$, PDF\#054-0887 as a reference, Figure 4(b)) existed together with peaks of the original $\mathrm{O}_{3}$-layered LiNMC. Indeed, the peaks of the new phase shifted to lower $2 \theta$ degrees demonstrated the increase of distance between adjacent slabs due to the insertion of bigger $\mathrm{Na}^{+}$ions (ionic radius of $\mathrm{Na}^{+}$ion is $1.02 \AA$, compared to $0.76 \AA$ of $\mathrm{Li}^{+}$ion [28]). The lattice parameters were calculated using hexagonal symmetry and $R-3 \mathrm{~m}$ space group, typically, $a=b=2.8555 \AA$; $c=14.2109 \AA$; and $\mathrm{V}=100.35 \AA^{3}$ for the pristine LiNMC and $a=b=2.8886 \AA ; c=16.0428 \AA ; \mathrm{V}=115.93 \AA$ for the sodiated $\mathrm{Na}_{\mathrm{y}} \mathrm{NMC}$. The values of the electrochemically synthesized $\mathrm{Na}_{\mathrm{y}} \mathrm{NMC}$ are lower than those of the chemically synthesized NaNMC $[8,9]$, possibly because of the introduction of lithium-ion trapped in the slab which has a shorter metaloxygen bond length than that of sodium analog.

The surface roughness (as seen in Figure 5) combining with lattice strain induced by the insertion of bigger size sodium-ion contributed to the broadening of collected diffraction peaks after sodiation. Furthermore, the XRD pattern collected after few cycles (the highest pattern in Figure 4(a)) demonstrates only the peaks of $\mathrm{O}_{3}-\mathrm{Na}_{\mathrm{y}} \mathrm{NMC}$, which is similar to the pattern of the first sodiation stage; hence, it revealed that the $\mathrm{O}_{3}$-type structure remained stable after cycling. The XRD results indicated that the concentration of lithium-ion decreased to a minimum after the second discharge leading to the vanishing of the $\mathrm{Li}_{\mathrm{x}} \mathrm{NMC}$ phase.

EIS spectra of the electrode at a different stage was investigated (Figure 4(c)). The first assemble electrode in lithium half-cell and sodium half-cell (the small figure inside Figure 4(c)) is characterized by two depressed semicircles of charge transfer processes and a long-sloping tail of ionic diffusion. The charge transfer process could be divided by 


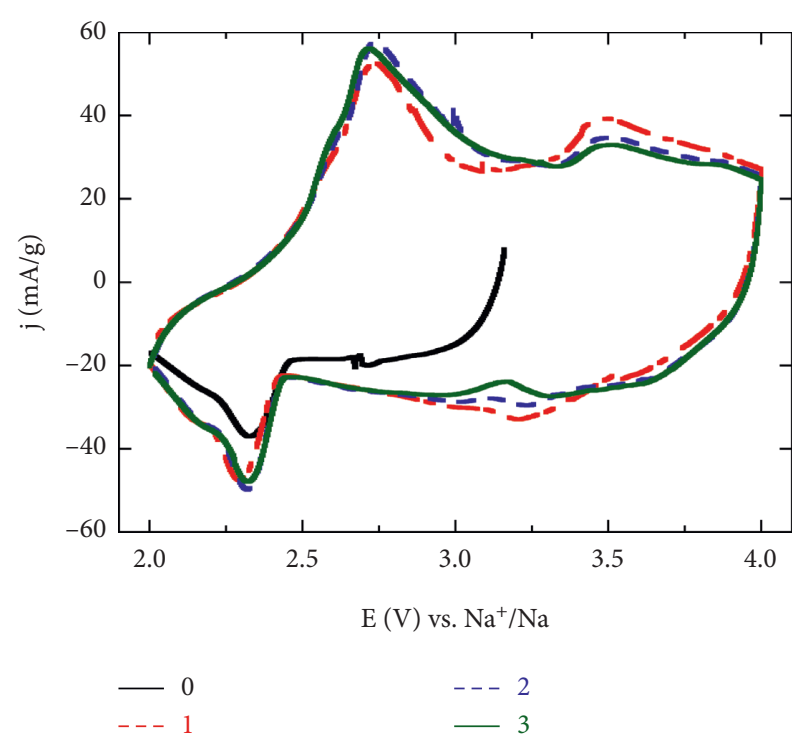

(a)

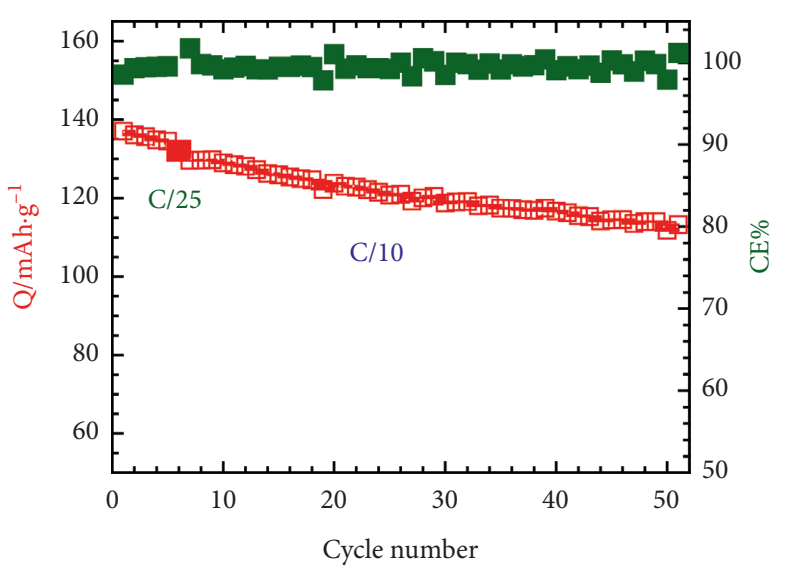

(c)

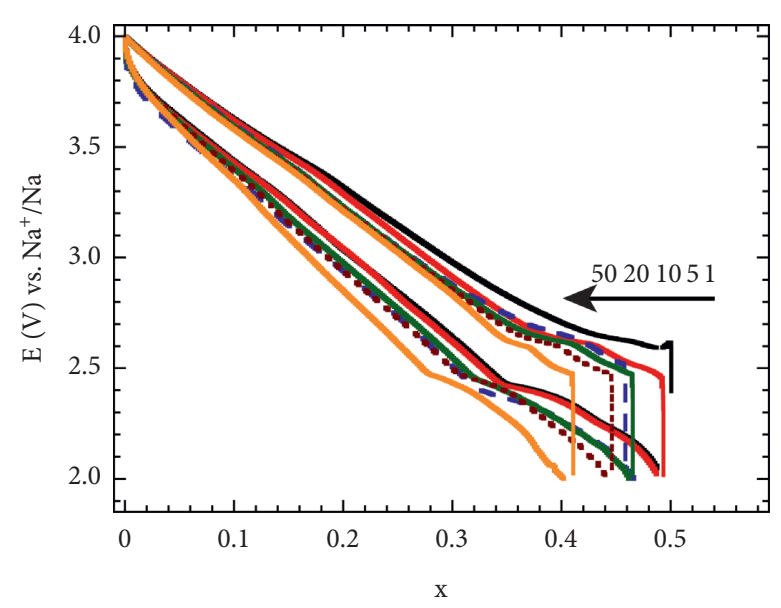

(b)

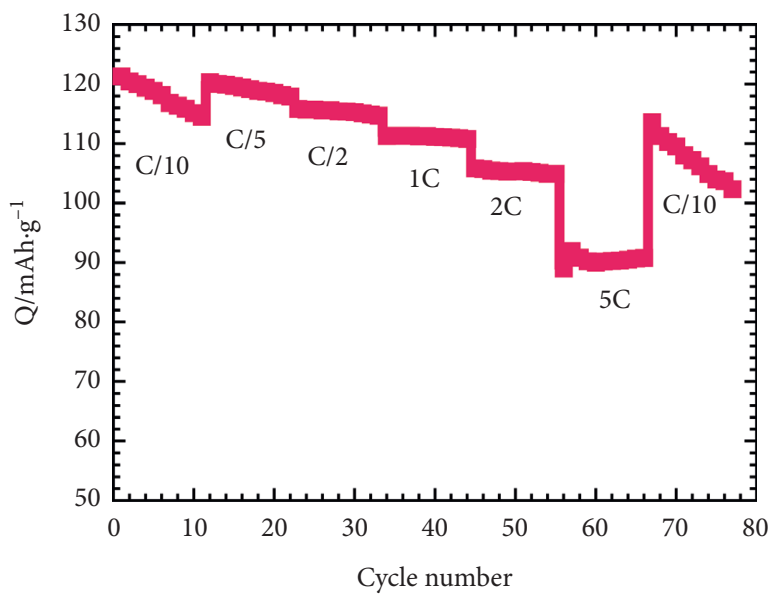

(d)

Figure 3: Electrochemical behavior of the sodiated $\mathrm{Na}_{\mathrm{z}} \mathrm{NMC}$ in half-cell of $\mathrm{Na}\left\|\mathrm{NaClO}_{4} / \mathrm{PC}-\mathrm{FEC}(98: 2)\right\| \mathrm{Na}_{\mathrm{z}} \mathrm{NMC}$. (a) CV curves at a scan rate of $0.1 \mathrm{mV} \mathrm{s}^{-1}$. (b) The galvanostatic charge-discharge profiles at the rate of $\mathrm{C} / 25$ and $\mathrm{C} / 10$. (c) The specific capacity and Coulombic efficiency versus cycles and (d) rate capability test.

small charge transfer resistance of SEI (Solid Electrolyte Interface) layered appearing at high frequency and another charge transfer resistance of the electrode at the medium-tolow frequency. The diameter of the semicircles is equal to the resistance values of the corresponding process. It is observed that the lower specific frequency at the top of semicircles and the higher charge transfers were obtained in sodium half-cell possibly indicating slower kinetic of sodium intercalation compared to lithium intercalation into the same delithiated host [20]. EIS spectrum after sodiation exhibits three semicircles as previously reported on $\mathrm{Na}_{\mathrm{y}} \mathrm{NMC}$ electrode [29]. The first and second semicircles observed at high frequency represent SEI and charge transfer of the electrode, respectively. Regarding the diameter of the first semicircle, the resistance of SEI layered did not change much after the $1^{\text {st }}$ cycle indicating a stable formation of the SEI layer before and after cycling. However, the diameter of the second semicircle changed with cycling. The EIS spectra obtained at the $1^{\text {st }}$ discharge showed that the charge transfer resistance obviously reduces due to electrolyte permeability and increases gradually during cycling. However, the charge transfer resistance enlarges by cycle and the value obtained at the $30^{\text {th }}$ cycle is approximately 1.5 times higher than that obtained at the $1^{\text {st }}$ cycle. Since the specific frequency could be an indicator for the change of chemical composition at the surface [30], the significant reduction of a specific frequency at the $30^{\text {th }}$ cycle presumably coincides with the change of electrode composition and phase component given by the XRD result, Figure 4(a), and the observed degradation of the electrode.

It is noticeable that the diffusion tail of the initial EIS changing into an elongated semicircle after the first discharge ( $1^{\text {st }}$ sodiation) indicated a change in diffusion mode from semi-infinite to finite diffusion. This result could be 


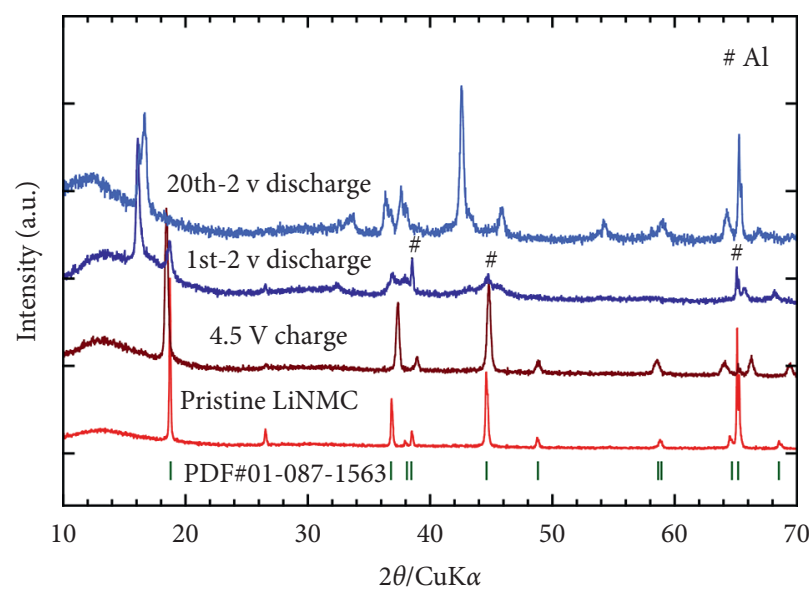

(a)

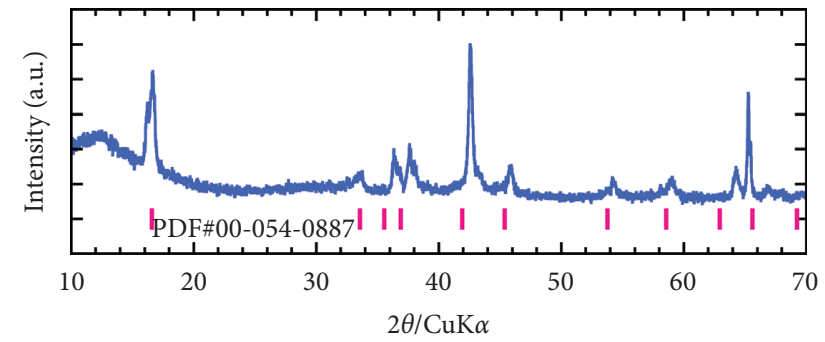

(b)

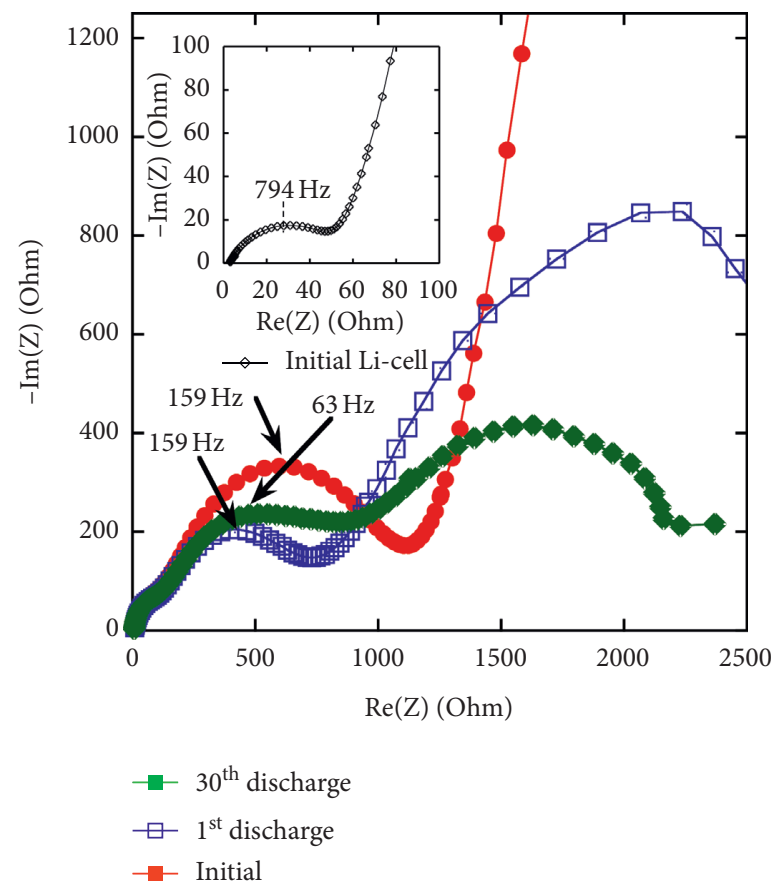

(c)

FIGURE 4: (a) XRD of pristine LiNMC, $2^{\text {nd }}$ discharge, and $20^{\text {th }}$ discharge of new sodium cathode; (b) XRD of the new sodium cathode at the $20^{\text {th }}$ discharge; and (c) EIS spectra of the LiNMC cathode in Li-cell and the new sodium cathode at various stages in Na-cell.

explained by the restriction of sodium-ions diffusion in the sodium-rick phase outside the particles and/or in the porous structure of the cathode after sodiation.

SEM images of the pristine electrode LiNMC and the sodiated $\mathrm{Na}_{\mathrm{z}} \mathrm{NMC}$ are given in Figure 5. LiNMC is crystallized in spherical shape particles with a diameter of about $500 \mathrm{~nm}$ agglomerated in macrosize spherical shape clusters (Figures 5(a)-5(c)). The particles are covered by small carbon beads with $50 \mathrm{~nm}$ diameters. Overall, the LiNMC cathode has a uniform distribution of components facilitating their electrochemical performance. After the sodiation process, SEM images in Figures 5(e) and 5(g) displayed several cracks and the round shape particles become rough.
Carbon layered (red circled in Figure 5(e)) seemed to be removed from the surface of $\mathrm{Na}_{\mathrm{y}} \mathrm{NMC}$; thus, $\mathrm{Na}_{\mathrm{y}} \mathrm{NMC}$ particles mostly are exposed in SEM images. The change of particle size could not be observed but the lattice parameters increased as mentioned. Besides, the needle-like crystals present in SEM images might be residual sodium salt remaining after washing but not likely the product of the reaction between the electrode with moisture and air as [31].

The SEM results revealed that the change of electrode's morphology, leaching of carbon coating, contributed to the increase of resistance and gradual degradation of electrode performance during the cycle. Moreover, this allowed side reactions such as electrolyte decomposition to occur that 


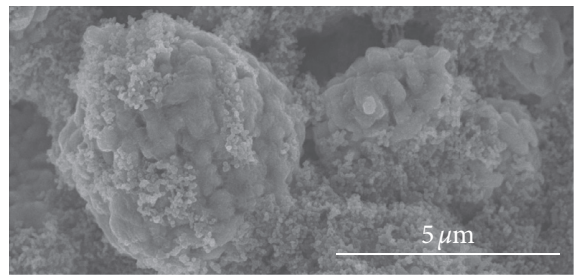

(a)

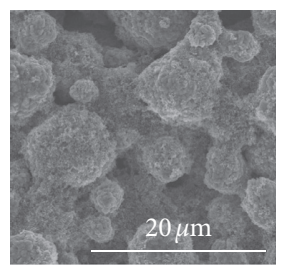

(b)

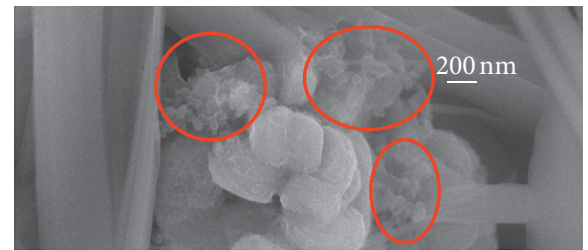

(e)

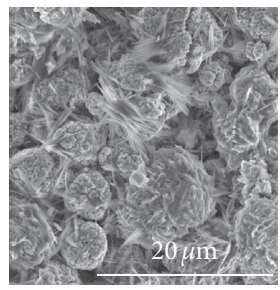

(f)

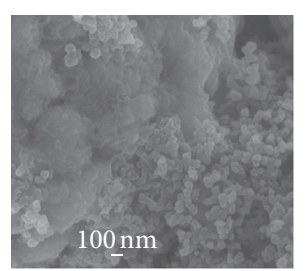

(c)

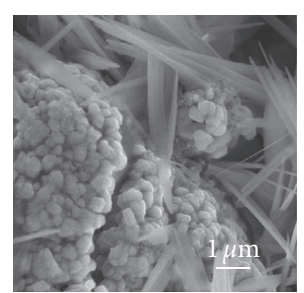

(g)

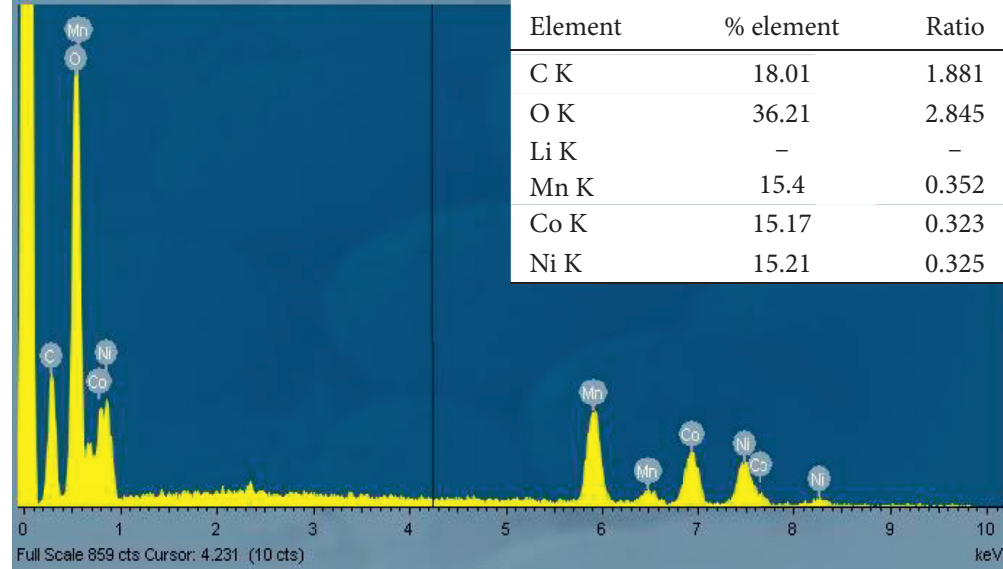

(d)

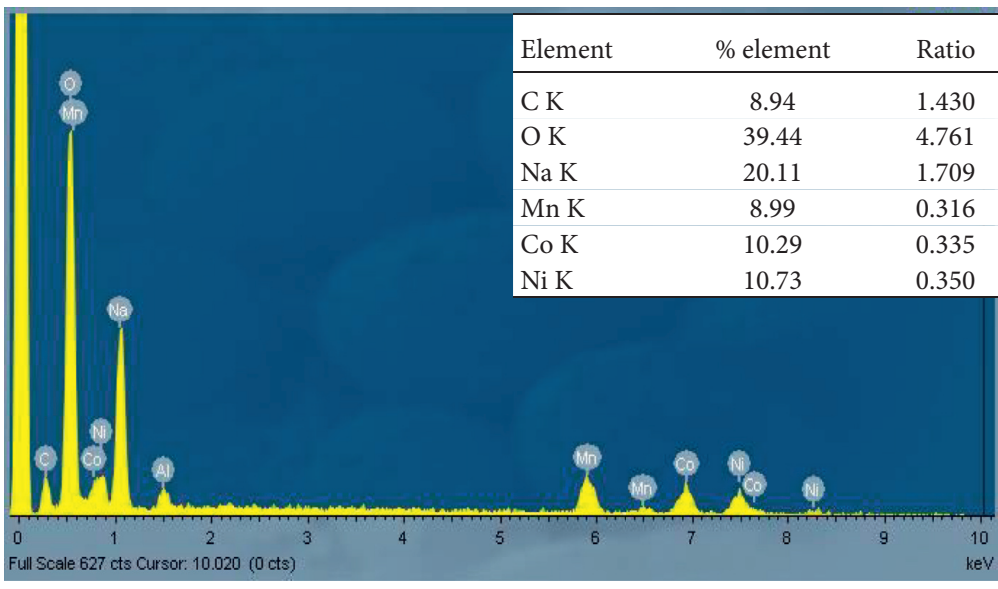

(h)

Figure 5: SEM images of the pristine electrode LiNMC (a-c) and the EDX spectrum (d). SEM images of the sodiated $\mathrm{Na}_{\mathrm{y}} \mathrm{NMC}$ after 50 cycles in sodium half-cell (e-g) and the EDX spectrum (h). EDX results for elements percentage were put inside the corresponding EDX spectrums.

consumed the electron and reduce the current efficiency resulting in fast degradation of capacity at low current density as seen in Figures 3(c) and 3(d).

EDX results for elements analysis are also inserted in Figures 5(e) and 5(f). Medium and heavy elements (transition metals) could be mostly detected for LiNMC and the sodiated $\mathrm{Na}_{\mathrm{y}} \mathrm{NMC}$; only lithium cation is negligible due to the lightweight. The composition of the electrode seems to change after cycling in sodium half-cell. EDX results of the new sodiated cathode displayed a relatively high concentration of sodium as expected, but a slight decrease in the concentration of transition metals was obtained due to sodium salt residue in the cathode surface.

Although the sodium-ion migration in the oxide depends on the concentration of sodium-ion in the host and the potential and is affected by the phase transition [32], the apparent diffusion coefficient of $\mathrm{Na}^{+}$ion intercalated into the sodiated structure was investigated as an indicator for kinetic of the electrode reaction. According to XRD results, the insertion of $\mathrm{Na}^{+}$into lithiated LiNMC leads to the formation of an O3-like layered structure after the first discharging. It is well known that the intensity of oxidation/ reduction peak is proportional to the square root of scan rate demonstrated by the Randles-Sevcik equation [33-36]:

$$
\mathrm{I}=2.69 \times 10^{5} \mathrm{n}^{3 / 2} \mathrm{AD}^{1 / 2} \mathrm{Cv}^{1 / 2},
$$

where I (A), n, A $\left(\mathrm{cm}^{2}\right), \mathrm{D}\left(\mathrm{cm}^{2} \mathrm{~s}^{-1}\right), \mathrm{C}\left(\mathrm{mol} \mathrm{cm}{ }^{-3}\right)$, and $v$ $\left(\mathrm{V} \mathrm{s}^{-1}\right)$ are the current at peak, electrode area, diffusion coefficient, and concentration of sodium-ion at full discharge state at specific scan rate, respectively. The concentration of sodium-ion could be calculated as a ratio between the number of intercalated sodium-ion at the equilibrium discharge $\left(0.53\right.$ ion $\left.\mathrm{Na}^{+}\right)$and the volume cell of the $\mathrm{O}_{3}$ $\mathrm{Na}_{\mathrm{x}} \mathrm{NMC}$ sodiated phase. As could be seen in Figure 6(a), the shape of the CV curves did not change after several scan rates. Moreover, one pair of redox peaks at $2.7 \mathrm{~V}$ and $2.2 \mathrm{~V}$ corresponding to the phase transition from $\mathrm{O}_{3}$ to $\mathrm{P}_{3}$ phase during the sodium extraction/insertion process could be seen. The peak currents at each scan rate were plotted as a function of scan rate square root (in Figure 6(b)). The linear relationship of both oxidation and reduction peaks indicates that equation (1) is satisfied with highly acceptable $R^{2}$ values $>99.8 \%$. 


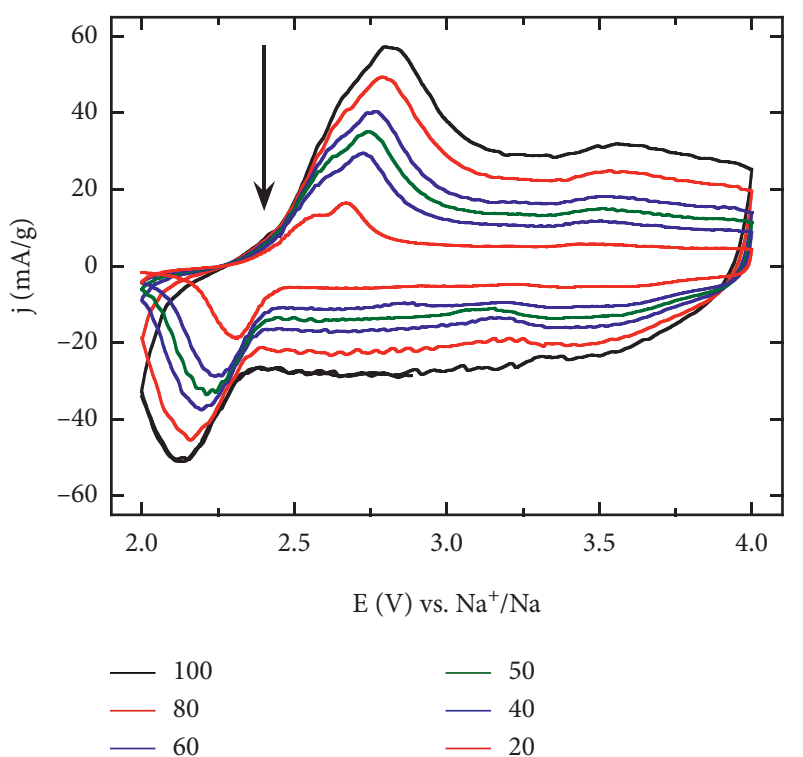

(a)

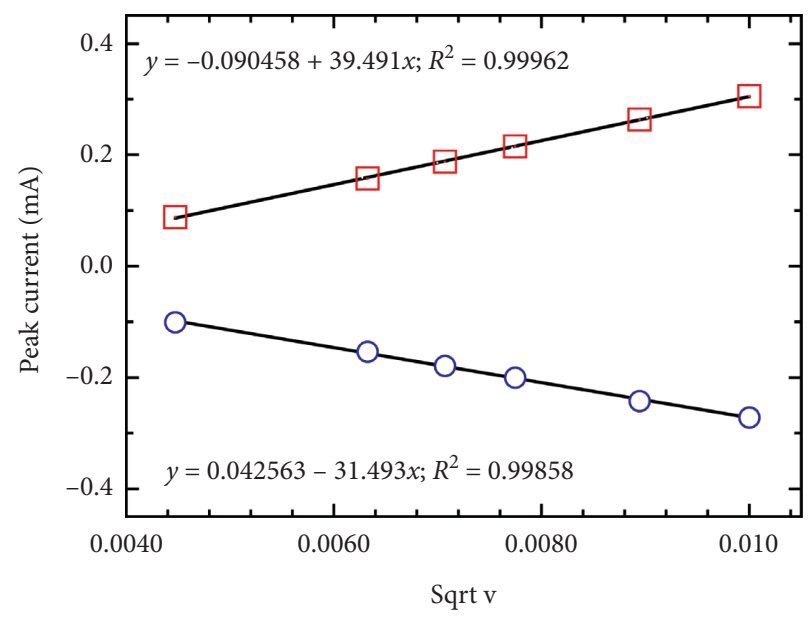

(b)

FIGURE 6: CV curve of sodium intercalation/deintercalation into $\mathrm{Li}_{\mathrm{x}} \mathrm{NMC}$ at various scan rates (a). The plot of peaks current as a function of the square root of the scan rate (b).

The diffusion coefficient could be deduced from the slope of the linear lines, as equation (1). The diffusion coefficients calculated are $6.75 \times 10^{-11} \mathrm{~cm}^{2} \mathrm{~s}^{-1}$ and $4.0 \times 10^{-11} \mathrm{~cm}^{2} \mathrm{~s}^{-1}$ for oxidation and reduction scan, respectively. The values of diffusion coefficients are quite close to the value obtained by GITT technique in the biphasic region of the sol-gel LiNMC [13]. There are many reasons to explain for relatively low diffusion coefficient including cathode damage due to conductive carbon removing so as to prevent the transportation of sodium to the surface.

\section{Conclusion}

The new sodium insertion host was prepared by the sodiation of LiNMC and evaluated the sodium intercalation behaviors. It was demonstrated that the $\mathrm{O}_{3}$-type structure of the pristine LiNMC remained after the insertion of $\mathrm{Na}^{+}$ion. Basically, the delithiated host $\mathrm{Na}_{\mathrm{y}} \mathrm{NMC}$ could receive a proportional number of sodium-ions intercalated into the structure as most lithium-ion extraction to give higher capacity than the synthesized NaNMC so a high charge cutoff voltage was applied to extract more lithium-ions, but its capacity is incomparable to lithium analog capacity due to bigger sodium-ions than lithium ones. Sodiated $\mathrm{Na}_{\mathrm{z}} \mathrm{NMC}$ cathode displays a potential performance with $85 \%$ capacity retention after 50 cycles. However, the particle cracking, cathode damage due to cell disassemble, electrolyte decomposition, and conductive carbon removing might be responsible for the structural deterioration and should be resolved to enhance the stability of $\mathrm{Na}^{+}$ion intercalation. Once this obstacle can be overcome, the ion-exchange method gives a direct, onestep, facile way to prepare the cathode $\mathrm{Na}_{\mathrm{y}} \mathrm{NMC}$ for highperformance Na-ion batteries.

\section{Data Availability}

The data are available upon request.

\section{Conflicts of Interest}

The authors declare no conflicts of interest.

\section{Acknowledgments}

The authors would like to thank the University of Technology, Ho Chi Minh City, VNU-HCM, for XRD measurement and the researchers in APCLab for technical support. This research was funded by the Viet Nam National University-Ho Chi Minh City (VNU HCM) through the research project code C2020-18-24.

\section{References}

[1] P. K. Nayak, L. Yang, W. Brehm, and P. Adelhelm, "From lithium-ion to sodium-ion batteries: advantages, challenges, and surprises," Angewandte Chemie International Edition, vol. 57, no. 1, pp. 102-120, 2018.

[2] N. Nitta, F. Wu, J. T. Lee, and G. Yushin, "Li-ion battery materials: present and future," Materials Today, vol. 18, no. 5, pp. 252-264, 2015.

[3] N. Yabuuchi, K. Kubota, M. Dahbi, and S. Komaba, "Research development on sodium-ion batteries," Chemical Reviews, vol. 114, no. 23, pp. 11636-11682, 2014.

[4] M. Sawicki and L. L. Shaw, "Advances and challenges of sodium ion batteries as post lithium ion batteries," RSC Advances, vol. 5, no. 65, pp. 53129-53154, 2015.

[5] R. C. Massé, E. Uchaker, and G. Cao, "Beyond Li-ion: electrode materials for sodium- and magnesium-ion batteries," Science China Materials, vol. 58, no. 9, pp. 715-766, 2015. 
[6] S. Kuze, J. Kageura, S. Matsumoto et al., "Development of a sodium ion secondary battery," Sumitomo Kagaku, vol. 2013, pp. 1-13, 2013.

[7] S. G. Ivanova, E. N. Zhecheva, and R. K. Stoyanova, "Sodium deficient transition metal oxides $\mathrm{Na}_{1 / 2} \mathrm{Co}_{1 / 3} \mathrm{Ni}_{1 / 3} \mathrm{Mn}_{1 / 3} \mathrm{O}_{2}$ as alternative electrode materials for lithium-ion batteries," Journal of Materials Chemistry A, vol. 48, no. A, pp. 88-94, 2016.

[8] J.-Y. Hwang, C. S. Yoon, I. Belharouak, and Y.-K. Sun, "A comprehensive study of the role of transition metals in $\mathrm{O}_{3}$ type layered $\mathrm{Na}\left[\mathrm{Ni}_{\mathrm{x}} \mathrm{Co}_{\mathrm{y}} \mathrm{Mn}_{\mathrm{z}}\right] \mathrm{O}_{2}(\mathrm{x}=1 / 3,0.5,0.6$, and 0.8$)$ cathodes for sodium-ion batteries," Journal of Materials Chemistry A, vol. 4, no. 46, pp. 17952-17959, 2016.

[9] M. Sathiya, K. Hemalatha, K. Ramesha, J.-M. Tarascon, and A. S. Prakash, "Synthesis, structure, and electrochemical properties of the layered sodium insertion cathode material: $\mathrm{NaNi}_{1 / 3} \mathrm{Mn}_{1 / 3} \mathrm{Co}_{1 / 3} \mathrm{O}_{2}$," Chemistry of Materials, vol. 24, no. 10, pp. 1846-1853, 2012.

[10] G.-L. Xu, R. Amine, Y.-F. Xu et al., "Insights into the structural effects of layered cathode materials for high voltage sodium-ion batteries," Energy \& Environmental Science, vol. 10, no. 7, pp. 1677-1693, 2017.

[11] A. M. Hashem, A. E. Abdel-Ghany, H. M. Abuzeid et al., " $\mathrm{LiNi}_{1 / 3} \mathrm{Mn}_{1 / 3} \mathrm{Co}_{1 / 3} \mathrm{O}_{2}$ synthesized by sol-gel method: structure and electrochemical properties," ECS Transactions, vol. 50, no. 24, pp. 91-96, 2013.

[12] N. Yabuuchi and T. Ohzuku, "Electrochemical behaviors of $\mathrm{LiCo}_{1 / 3} \mathrm{Ni}_{1 / 3} \mathrm{Mn}_{1 / 3} \mathrm{O}_{2}$ in lithium batteries at elevated temperatures," Journal of Power Sources, vol. 146, no. 1-2, pp. 636-639, 2005.

[13] T. Van Man, H. L. T. Nguyen, L. P. P. Nam, N. D. Linh, P. L. B. An, and L. M. L. Phung, "Electrochemical Na-migration into delithiated phase $\mathrm{LizNi}_{1 / 3} \mathrm{Mn}_{1 / 3} \mathrm{Co}_{1 / 3} \mathrm{O}_{2}$ : structure and electrochemical properties," Journal of The Electrochemical Society, vol. 165, no. 7, pp. A1558-A1562, 2018.

[14] L. Yang, X. Li, J. Liu et al., "Lithium-doping stabilized highperformance $\mathrm{P}_{2}-\mathrm{Na}_{0.66} \mathrm{Li}_{0.18} \mathrm{Fe}_{0.12} \mathrm{Mn}_{0.7} \mathrm{O}_{2}$ cathode for sodium ion batteries," Journal of the American Chemical Society, vol. 141, no. 16, pp. 6680-6689, 2019.

[15] S. Zheng, G. Zhong, M. J. McDonald et al., "Exploring the working mechanism of $\mathrm{Li}_{+}$in $\mathrm{O}_{3}$-type $\mathrm{NaLi}_{0.1} \mathrm{Ni}_{0.35} \mathrm{Mn}_{0.55} \mathrm{O}_{2}$ cathode materials for rechargeable Na-ion batteries," Journal of Materials Chemistry A, vol. 4, no. 23, pp. 9054-9062, 2016.

[16] C. Liu, J. Li, P. Zhao, W. Guo, and X. Yang, "Fast preparation of $\mathrm{Na}_{0.44} \mathrm{MnO}_{2}$ nanorods via a high $\mathrm{NaOH}$ concentration hydrothermal soft chemical reaction and their lithium storage properties," Journal of Materials Chemistry A, vol. 17, no. 3, p. 8, 2015.

[17] S. Bublil, M. Fayena-Greenstein, and M. Talyanker, "Na-ion battery cathode materials prepared by electrochemical ion exchange from alumina-coated $\mathrm{Li}_{1+\mathrm{x}} \mathrm{Mn}_{0.54} \mathrm{Co}_{0.13} \mathrm{Ni}_{0.1+\mathrm{y}} \mathrm{O}_{2}$," Journal of Materials Chemistry A, vol. 6, no. 30, pp. 1481614827, 2018.

[18] N. V. Kosova, D. O. Rezepova, S. A. Petrov, and A. B. Slobodyuk, "Electrochemical and chemical $\mathrm{Na}_{+} / \mathrm{Li}_{+}$ion exchange in Na-based cathode materials: $\mathrm{Na}_{1.56} \mathrm{Fe}_{1.22} \mathrm{P}_{2} \mathrm{O}_{7}$ and $\mathrm{Na}_{3} \mathrm{~V}_{2}\left(\mathrm{PO}_{4}\right)_{2} \mathrm{~F}_{3}$," Journal of The Electrochemical Society, vol. 164, no. 1, pp. A6192-A6200, 2017.

[19] W. Tang, X. Song, Y. Du et al., "High-performance $\mathrm{NaFePO}_{4}$ formed by aqueous ion-exchange and its mechanism for advanced sodium ion batteries," Journal of Materials Chemistry A, vol. 4, no. 13, pp. 4882-4892, 2016.
[20] C. Heubner, B. Matthey, T. Lein et al., "Insights into the electrochemical $\mathrm{Li} / \mathrm{Na}$-exchange in layered $\mathrm{LiCoO}_{2}$ cathode material," Energy Storage Materials, vol. 27, pp. 377-386, 2020.

[21] C. Delmas, C. Fouassier, and P. Hagenmuller, "Structural classification and properties of the layered oxides," Physica $B+C$, vol. 99, no. 1-4, pp. 81-85, 1980 .

[22] H. Zhu, Q. Li, X. Gong, K. Cao, and Z. Chen, "Enhanced high voltage performance of chlorine/bromine Co-doped lithium nickel manganese cobalt oxide," Crystals, vol. 8, no. 11, p. 425, 2018.

[23] R. Jung, M. Metzger, F. Maglia, C. Stinner, and H. A. Gasteiger, "Chemical versus electrochemical electrolyte oxidation on $\mathrm{NMC}_{111}, \mathrm{NMC}_{622}, \mathrm{NMC}_{811}$, LNMO, and conductive carbon," The Journal of Physical Chemistry Letters, vol. 8, no. 19, pp. 4820-4825, 2017.

[24] R. Jung, M. Metzger, F. Maglia, C. Stinner, and H. A. Gasteiger, "Oxygen release and its effect on the cycling stability of $\mathrm{LiNi}_{\mathrm{x}} \mathrm{Mn}_{\mathrm{y}} \mathrm{Co}_{\mathrm{z}} \mathrm{O}_{2}(\mathrm{NMC})$ cathode materials for $\mathrm{Li}$ ion batteries," Journal of The Electrochemical Society, vol. 164, no. 7, pp. A1361-A1377, 2017.

[25] J. Xu, D. H. Lee, R. J. Clément et al., "Identifying the critical role of $\mathrm{Li}$ substitution in $\mathrm{P}_{2}-\mathrm{Na}_{\mathrm{x}}\left[\mathrm{Li}_{\mathrm{y}} \mathrm{Ni}_{\mathrm{z}} \mathrm{Mn}_{1-\mathrm{y}-\mathrm{z}}\right] \mathrm{O}_{2}(0<x, y$, $z<1)$ intercalation cathode materials for high-energy $\mathrm{Na}$-ion batteries," Chemistry of Materials, vol. 26, no. 2, pp. 1260-1269, 2014.

[26] S.-M. Oh, S.-T. Myung, J.-Y. Hwang, B. Scrosati, K. Amine, and Y.-K. Sun, "High capacity $\mathrm{O}_{3}$-type $\mathrm{Na}$ $\left[\mathrm{Li}_{0.05}\left(\mathrm{Ni}_{0.25} \mathrm{Fe}_{0.25} \mathrm{Mn}_{0.5}\right)_{0.95}\right] \mathrm{O}_{2}$ cathode for sodium ion batteries," Chemistry of Materials, vol. 26, no. 21, pp. 6165-6171, 2014.

[27] X. Cao, Y. Zhao, L. Zhu et al., "Synthesis and characterization of $\mathrm{LiNi}_{1 / 3} \mathrm{Co}_{1 / 3} \mathrm{Mn}_{1 / 3} \mathrm{O}_{2}$ as cathode materials for Li-ion batteries via an efficacious sol- gel method," International Journal of Electrochemical Science, vol. 11, pp. 5267-5278, 2016.

[28] N. V. Kosova and A. A. Shindrov, "Effect of mixed $\mathrm{Li}_{+} / \mathrm{Na}_{+}$ion electrolyte on electrochemical performance of $\mathrm{Na}_{4} \mathrm{Fe}_{3}\left(\mathrm{PO}_{4}\right)_{2} \mathrm{P}_{2} \mathrm{O}_{7}$ in hybrid batteries," Batteries, vol. 5, no. 2, p. 39, 2019.

[29] H. Van Nguyen, H. T. N. Nguyen, N. L. T. Huynh, A. L. B. Phan, M. Van Tran, and P. M. L. Le, "A study of the electrochemical kinetics of sodium intercalation in $\mathrm{P}_{2} / \mathrm{O}_{1} / \mathrm{O}_{3}$ $\mathrm{NaNi}_{1 / 3} \mathrm{Mn}_{1 / 3} \mathrm{Co}_{1 / 3} \mathrm{O}_{2 / 3} \mathrm{Mn}_{1 / 3} \mathrm{Co}_{1 / 3} \mathrm{O}_{2}$," Journal of Solid State Electrochemistry, vol. 24, no. 1, p. 57, 2019.

[30] J. Conder and C. Villevieille, "How reliable is the Na metal as a counter electrode in Na-ion half cells?" Chemical Communications, vol. 55, no. 9, pp. 1275-1278, 2019.

[31] Y. You, A. Dolocan, W. Li, and A. Manthiram, "Understanding the air-exposure degradation chemistry at a nanoscale of layered oxide cathodes for Sodium-ion batteries," Nano Letters, vol. 19, no. 1, pp. 182-188, 2019.

[32] Y. Zhu and C. Wang, "Galvanostatic intermittent titration technique for phase-transformation electrodes," The Journal of Physical Chemistry C, vol. 114, no. 6, pp. 2830-2841, 2010.

[33] H.-R. Yao, P.-F. Wang, Y. Wang, X. Yu, Y.-X. Yin, and Y.-G. Guo, "Excellent comprehensive performance of Nabased layered oxide benefiting from the synergetic contributions of multimetal ions," Journal of Physical Chemistry C, vol. 7, no. 15, 2017.

[34] P.-F. Wang, Y. You, Y.-X. Yin, and Y.-G. Guo, “An O $\mathrm{O}_{3}$-type $\mathrm{NaNi}_{0.5} \mathrm{Mn}_{0.5} \mathrm{O}_{2}$ cathode for sodium-ion batteries with improved rate performance and cycling stability," Journal of Materials Chemistry A, vol. 4, no. 45, pp. 17660-17664, 2016.

[35] Q. Zhu, B. Nan, Y. Shi et al., " $\mathrm{Na}_{3} \mathrm{~V}_{2}\left(\mathrm{PO}_{4}\right)_{3} / \mathrm{C}$ nanofiber bifunction as anode and cathode materials for sodium-ion 
batteries," Journal of Solid State Electrochemistry, vol. 21, no. 10, pp. 2985-2995, 2017.

[36] E. de la Llave, V. Borgel, K.-J. Park et al., "Comparison between Na-ion and Li-ion cells: understanding the critical role of the cathodes stability and the anodes pretreatment on the cells behavior," ACS Applied Materials \& Interfaces, vol. 8, no. 3, pp. 1867-1875, 2016. 